\title{
LOS FUTUROS MÉDICOS
}

Editorial del Dr. Julio Manrique

En los exámenes del año escolar que termina en este mes se reprobaron en la Facultad de Medicina algo asi como el 20 por 100 de los alumnos que se presentaron a examen, cifra que ha puesto miedo en los ánimos de los que intentan dedicarse al estudio de la ciencia médica y que ha dado lugar a varios comentarios de parte de aquellos que se interesan en la marcha de esta clase de estudios en Colombia. El caso es fácil de analizar. $O$ es que los estudiantes trabajan menos, o es que los profesores exigen más; porque no es de suponer que en poco tiempo haya habido un cambio en la mentalidad de los jóvenes, desventajoso para los que ahora estudian si se compara con la inteligencia de los que estudiaron en épocas anteriores. A la vista salta que lo que tiene que aprender quien quiera estar al corriente de los modernos estudios anatómicos ó fisiológicos, quien quiera realmente saber Histología o Patología general o especial, tiene que estudiar ahora mucho más que hace veinte años. No hay sino comparar el tratado de anatomía de Testut con el de Sapey, o el texto de Patología externa con el que servía hace pocos años, lo que hace ver claro que hoy hay que estudiar más que antes; nos queda por averiguar si los estudiantes asi lo hacen. El tipo de estudiante ha cambiado mucho de unos diez o quince años para acá y la tradición del mozo, un tanto truhan y aventurero que recordaba a sus antepasados de Oviedo o de Cigüenza, va desapareciendo poco a poco. Los de una generación que todavía vive y que todavía brilla nos cuentan con agrado las sabrosas noches de verbena y las artificiosas malas partidas que, a profesores y pasantes, solian jugarles los alumnos internos de Santa Inés, y a veces en la intimidad, no sin emoción, nos hablan de la romántica serenatá en la calleja extraviada, en la que, acompañada por guitarras y tiples, la clara voz de un interno rompia el silencio de la noche con esas tristes canciones que entonces conmovian tan hondamente los corazones femeninos, y con orgullo nos hablan estos nuestros colegas de la pobreza en que vivian que muy rara vez les permitía una humilde cena a escote el sábado por la noche después de asistir al hoy llamado paraiso en el único teatro de la ciudad. Muchas veces hemos visto frentes arrugadas serenarse, y gestos de amargura cambiarse en plácida sonrisa al recuerdo de esos días felices en que, con la bolsa vacía y el traje raído, se triunfaba en los recién exámenes de la vieja Facultad.

El estudiante de hoy viste a la moda, va a fiestas $y$ a tertulias, va con frecuencia al cinematógrafo y es asiduo concurrente al Colón y al Municipal. Ha aceptado con calor las nuevas ideas sobre la educación física y frecuentemente juega al "football" o ensaya guardias de sable o de florete. Sin duda sus maneras y su comportamiento para con sus condiscípulos y para con sus superiores es más correcto de los que solía ser dos lustros atrás, y a veces, no muy a menudo, el profesor se sorprende de lo mucho que aprenden, de lo mucho que saben algunos alumnos que resistirian comparación con cualquiera de los grandes estudiantes de antaño.

Hay una deducción que se desprende fácilmente de todas estas consideraciones, y es que para estudiar medicina hoy, se necesita tener raras condiciones de inteligencia y de consagración.

* Tomado de Repertorio de Medicina y Cirugía volumen V No. 3 de diciembre de 1913 
Los jóvenes no se pueden sustraer a esa corriente de la vida moderna que riega diversiones por dondequiera, la tarea del estudiante es muy fuerte y si no se tienen dotes especiales, menos es no intentar una empresa en que la derrota es fácil y en ocasiones definitiva. El éxito rara vez acompaña hoy a los médicos. Para descollar hay que trabajar duramente, y muchas veces a pesar de todo, la vida entera resulta corta para lamentar el error de haber abrazado la más árdua aunque la más noble de las profesiones.

\section{COMENTARIO}

\author{
Sergio A. Parra D. MD*
}

Desde principios del siglo XX el doctor Julio Manrique describía con asombro el cambio que observaba en el espíritu de los estudiantes de medicina de la época. Estudiantes que preferían devorar conocimiento a través del estudio de textos básicos de anatomía, patología y fisiología dejando atrás actividades culturales y lúdicas que les quitasen tiempo de estudio.
En la actualidad nuestros estudiantes muestran la otra cara de la moneda, pues nos encontramos con alumnos que prefieren lo resumido y enseñado en clases magistrales antes que profundizar en libros de texto, alumnos que al contrario de la descripción del doctor Manrique sobreponen la diversión al esfuerzo del estudio, que exigen mayores espacios de bienestar y deportivos, que no asisten a la biblioteca, que en vez de libros consultan el internet, alumnos con baja vocación a la investigación. Todo esto hace que la Institución Universitaria con sus docentes tengan que redoblar los esfuerzos para alcanzar el perfil ocupacional deseado para nuestros médicos.

Estos cambios a mi parecer obedecen a múltiples factores entre ellos la formación recibida en sus hogares y en su educación básica y media, a los diferentes fenómenos de globalización y al derecho maximizado al libre desarrollo de la personalidad. Es un reto entonces para nuestra institución de educación superior formar este grupo heterogéneo para que en el futuro, como lo hemos logrado hasta la fecha, sean excelentes profesionales de la medicina y lleven en alto el nombre de la Fundación Universitaria de Ciencias de la Salud.

* Rector, Fundación Universitaria de Ciencias de la Salud. Bogotá DC, Colombia. 